\title{
New members of the ctrA regulon: the major chemotaxis operon in Caulobacter is CtrA dependent
}

\author{
Susan E. Jones, $†$ N. L. Ferguson and M. R. K. Alley \\ Author for correspondence: M. R. K. Alley. Tel: +44 207594 5304. Fax: +44 2075945207. \\ e-mail:d.alley@ic.ac.uk
}

Department of Biochemistry, Imperial College of Science, Technology and Medicine, London SW7 2AY, UK

\begin{abstract}
The Caulobacter crescentus che promoter region consists of two divergent promoters, directing expression of the major chemotaxis operon and a novel gene cagA (chemotaxis associated gene A). Analyses of start sites by primer extension and alignment of the divergent promoters revealed significant similarities between them at the $\mathbf{- 3 5}$ promoter region. Both mcpA and cagA are differentially expressed in the cell cycle, with maximal activation of transcription in predivisional cells. The main difference between the mcpA and cagA promoters is that, in common with the fljK flagellin, cagA is expressed in swarmer cells. A cagA-lacZ promoter fusion that contains $\mathbf{3 6}$ bases of untranslated mRNA has sufficient information to segregate the lacZ transcript to swarmer cells. Expression of mcpA and cagA was dependent on DNA replication. Transcriptional epistasis experiments were performed to identify potential regulators in the flagellar hierarchy. The sigma factor RpoN, which is required for flagellar biogenesis, is not required for $\operatorname{mcp} A$ and $\operatorname{cag} A$ expression. Mutations in the genes for the MS-ring and the switch complex (flagellar class II mutants) do not affect expression of mcpA and cagA. However, CtrA, an essential response regulator of flagellar gene transcription, is required.
\end{abstract}

Keywords: cell cycle, Caulobacter crescentus, transcriptional regulation, flagella

\section{INTRODUCTION}

Caulobacter crescentus undergoes obligate asymmetric cell division to yield two dissimilar cell types, a motile swarmer cell and a sessile stalked cell. The stalked cell is competent for DNA replication and can initiate cell growth to become a predivisional cell. However, the swarmer cell, which has a single polar flagellum, must differentiate into a non-motile stalked cell before cell growth and division can occur. Upon swarmer cell differentiation the single polar flagellum is ejected and a stalk synthesized at the site where the flagellum was previously located. This new stalked cell can initiate DNA replication and grow. Progression through the cell cycle is accompanied by synthesis of a new flagellum,

\footnotetext{
†Present address: Department of Biology, Imperial College of Science, Technology and Medicine, London SW7 2AY, UK.

Abbreviation: $\mathrm{HU}$, hydroxyurea.
}

which is placed at the cell pole opposite the stalk in the predivisional cell.

Epistatic analyses of flagellar mutants in C. crescentus have grouped the flagellar genes into four classes (Wu \& Newton, 1997). The essential response regulator $c t r A$, classified as a class I gene, controls class II genes, which include the genes for the switch complex, the MSring, the RpoN-dependent response regulator flbD (Ramakrishnan \& Newton, 1990) and its cognate kinase flbE (Wingrove \& Gober, 1996). Class III genes include the genes for the hook, the rod and the rings $(\mathrm{L}, \mathrm{P}, \mathrm{E})$, which require $f l b D$ and the alternate sigma factor $\sigma^{54}$ $(r p o N)$ for transcription (Brun \& Shapiro, 1992; Dingwall et al., 1992a). The class III genes also require the completion of the MS-ring switch complex for expression (Newton et al., 1989; Xu et al., 1989). The major flagellins $f l K$ and $f l j L$, which are class IV genes, require in addition to $r p o N$ and $f l b D$ (Brun \& Shapiro, 1992; Mullin \& Newton, 1993; Ninfa et al., 1989) the completion of the hook-basal body complex for expression (Mangan et al., 1999). At present it is unclear 


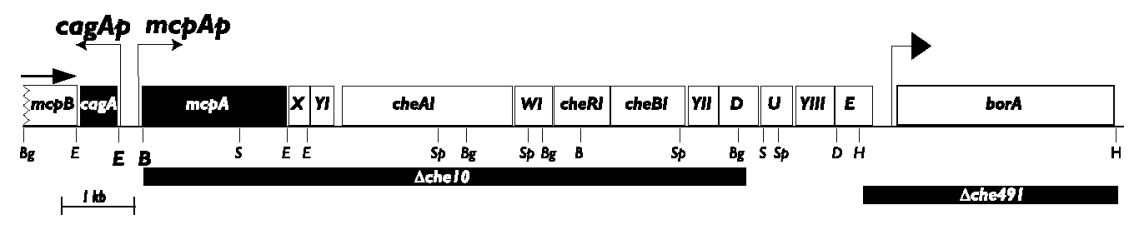

Fig. 1. The major chemotaxis operon of $C$. crescentus. Above the restriction map, boxes denote coding sequences for the respective genes. The boxes for the $m c p A$ and cagA genes are black. The black bars below the restriction map show the extent of the deletions. The borA gene encodes a putative homologue of a TonB-dependent outer membrane receptor protein. B, BamHI; Bg, Bglll; E, EcoRI; D, Dral; H, HindlII; N, Notl; Sp, Sphl; S, Sacl. The bold letters E and B in the restriction map denote the $339 \mathrm{bp} E c o \mathrm{RI}-B a m \mathrm{HI}$ fragment containing both $m c p A$ and cagA promoters.

how the three flagellin genes in the beta cluster $(f l j M N O)$ are regulated as they do not have consensus $\sigma^{54}$-binding motifs in their promoters, although their expression has a partial requirement for rpoN (Ely et al., 2000). Regulation of the remaining flagellin gene, fljJ, and the chemotaxis genes remains to be characterized.

The major chemotaxis operon of C. crescentus, shown schematically in Fig. 1, was identified using classical bacterial genetics; che mutants were isolated by transposon mutagenesis (Ely et al., 1986) and gene fusions were constructed to identify promoter elements (Alley et al., 1991). We have shown that this operon contains one chemoreceptor gene designated $m c p A$ (Alley et al., 1992) and 11 other chemotaxis genes (Tsai \& Alley, 2000). The genome sequence of C. crescentus (Nierman et al., 2001 ) is complete and the $4 \mathrm{Mb}$ genome accommodates numerous chemotaxis genes including 18 putative chemoreceptor homologues, seven of which have recently been shown to be cell-cycle regulated (Laub et al., 2000). The large number of chemotaxis genes in $C$. crescentus makes their regulation an attractive system to study, and by investigating chemotaxis gene regulation we hope to gain an insight into regulatory networks that integrate cell-cycle cues with chemotactic signals.

\section{METHODS}

Bacterial strains, plasmids and media. The strains and plasmids that were used in this study are listed in Table 1. C. crescentus was routinely grown in PYE complex medium (Ely, 1991) or M2G minimal medium (Ely, 1991) supplemented where appropriate with sucrose $(3 \%)$, tetracycline $\left(1 \mu \mathrm{g} \mathrm{ml}^{-1}\right)$, naladixic acid $\left(20 \mu \mathrm{g} \mathrm{ml}^{-1}\right)$, kanamycin $\left(5 \mu \mathrm{g} \mathrm{ml}^{-1}\right)$ and xylose $(0.2 \% \mathrm{w} / \mathrm{v})$. Escherichia coli strains were routinely grown in TB (Sambrook et al., 1989) for preparation of plasmids, or SOB (Sambrook et al., 1989) for preparation of electrocompetent cells. Plasmids were mobilized into C. crescentus from E. coli S17-1 by biparental conjugation (Ely, 1991). The Tn5 insertions in strains SC1032, SC1042, SC1055, SC1107, SC1117, SC1131, SC1132, SC1133, SC1138 (Ely \& Ely, 1989), PC5001 and PC5506 (Ohta et al., 1984) were transduced (Ely, 1991) into strain MRKA208.

Primer extension. Two primers were utilized to identify the transcriptional start site for cagA, CAGA1 (5'-GATCGGATATTTCATCCCGCT-3'), and CAGA2 (5'-TGCTCCTAG TAATGAATTCAGG-3') from Pharmacia Biotech. For $m c p A$ a single primer was utilized, MCPA1 (5'-GGATCCGTTTC-
ATCGCAAGG-3') from Pharmacia Biotech. Total RNA was isolated from late-exponential-phase wild-type cells (MRKA208) by hot phenol/SDS lysis (Salser et al., 1967). Primers were end-labelled with T4 polynucleotide kinase (Boehringer Mannheim) according to the manufacturers' instructions. Primer annealing to RNA ( $10 \mu \mathrm{g}$ total RNA, 200 fmol labelled primer) was carried out in hybridization buffer (40 mM PIPES, $1 \mathrm{mM}$ EDTA, $0.4 \mathrm{M} \mathrm{NaCl}, 80 \%$ formamide) at $30{ }^{\circ} \mathrm{C}$ overnight. Annealed primer/template mix was recovered by precipitation with ethanol. Extension with AMV reverse transcriptase (Promega) was performed as specified by the manufacturers at $42{ }^{\circ} \mathrm{C}$ for $1 \mathrm{~h}$. Reaction products were analysed by denaturing polyacrylamide electrophoresis on $6 \%$ polyacrylamide gels. Extension products were run alongside sequencing reactions carried out with the same primers.

Assays of promoter activity. The $\beta$-galactosidase activity of the promoter lacZ fusion constructs was assayed (Miller, 1972 ) in various genetic backgrounds from cultures grown at $28{ }^{\circ} \mathrm{C}$ to a mean $\mathrm{OD}_{600}$ of 0.8 . Five independent experiments were performed for each promoter fusion in every genetic background shown. In the CtrA depletion experiments, the activity of the promoter fusions was examined in three independent experiments. All $\beta$-galactosidase assays were carried out in duplicate.

Synchronization and immunoprecipitation. Pure populations of swarmer cells were isolated by Percoll (Pharmacia) density centrifugation from the strain MRKA779, which has the $\beta$ lactamase gene disrupted by $\mathrm{Tn} 5$. Cells were concentrated 10fold by centrifugation at $2500 \mathrm{~g}$ for $10 \mathrm{~min}$ and resuspended in $10 \mathrm{mM}$ phosphate buffer $\left(6.1 \mathrm{mM} \mathrm{Na}_{2} \mathrm{HPO}_{4}, 3.9 \mathrm{mM} \mathrm{KH}_{2} \mathrm{PO}_{4}\right.$ $\mathrm{pH} 7 \cdot 0$ ) mixed with an equal volume of Percoll (Pharmacia) and centrifuged $\left(10000 \mathrm{~g}, 20 \mathrm{~min}, 23^{\circ} \mathrm{C}\right)$. Swarmer cells were washed twice with $10 \mathrm{mM}$ phosphate buffer, then resuspended to $\mathrm{OD}_{600} 0 \cdot 4$ in $\mathrm{M} 2 \mathrm{G}$ and allowed to proceed synchronously through the cell cycle. Samples were taken every $20 \mathrm{~min}$, with a mean cell cycle length of $180 \mathrm{~min}$. Where progeny cells were examined, synchronous predivisional cells were allowed to divide. Following cell division, progeny swarmer and stalked cells were separated by Percoll gradient centrifugation as described before. Cell samples were lysed and prepared for immunoprecipitation essentially as described by Quon et al. (1996).

Inhibition of DNA synthesis. MRKA779 cultures harbouring plasmids reporting $m c p A$ and $c a g A$ expression were treated with hydroxyurea at $3 \mathrm{mg} \mathrm{ml}^{-1}$ (Osley et al., 1977). Samples were withdrawn at $10 \mathrm{~min}$ intervals and immunoprecipitations carried out as described before, using an antibody specific for $\beta$-galactosidase (CP laboratories). 
Table 1. Strains and plasmids

\begin{tabular}{|c|c|c|}
\hline Strain & Genotype, relevant characteristics & Reference \\
\hline \multicolumn{3}{|l|}{ E. coli } \\
\hline DH10B & $\begin{array}{l}\mathrm{F}^{-} m c r A \Delta(m r r-h s d R M S-m c r B C) \Delta l a c X 74 \phi 80 \mathrm{~d} l a c Z \Delta \mathrm{M} 15 \text { deoR recA1 end } 11 \\
\text { ara } \Delta 139 \mathrm{rpsL}\end{array}$ & GibcoBRL \\
\hline S17-1 & M294 : :RP4 2 (Tc : :Mu) (Km : :Tn7) & Simon et al. (1983) \\
\hline \multicolumn{3}{|l|}{ C. crescentus } \\
\hline MRKA208 & CB15N $\Delta$ bla6, synchronizable derivative of CB15 & M. R. K. Alley \\
\hline MRKA348 & CB15N sbla6 fliM196: : Tn5 & This study \\
\hline MRKA413 & CB15N sbla6 flbD198: : Tn5 & This study \\
\hline MRKA414 & CB15N sbla6 fliF601 : : Tn5 & This study \\
\hline MRKA442 & CB15N sbla6 flgH194: : Tn5 & This study \\
\hline MRKA446 & CB15N $\Delta b l a 6$ flhA608 : : Tn5 & This study \\
\hline MRKA520 & CB15N $\operatorname{ctr} A \Omega a a d A I x y l X p:: c t r A$ & Quon et al. (1996) \\
\hline MRKA590 & CB15N sbla6 rpoN610 : :Tn5 & This study \\
\hline MRKA642 & CB15N $\Delta$ bla6 flgK311 : :Tn5 & This study \\
\hline MRKA779 & CB15N bla101 : :Tn5 & This study \\
\hline MRKA667 & CB15N $\Delta$ bla6 flbG602: :Tn5, first gene in flgE operon & This study \\
\hline MRKA674 & $\mathrm{CB} 15 \mathrm{~N} \Delta$ bla $6(m c p A-$ cheD $)$ che 10 & This study \\
\hline MRKA773 & CB15N $\Delta$ bla6 $\Delta($ cheE-borA $)$ che $491 \Omega \mathrm{Cm}^{\mathrm{r}}$ & This study \\
\hline \multicolumn{3}{|l|}{ Plasmids } \\
\hline pRSZ6 & Broad-host-range bidirectional gus $A$, lacZ promoter fusion vector & M. R. K. Alley \\
\hline $\mathrm{pCH} 04$ & 339 bp EcoRI-Bam HI containing the che promoter in $\mathrm{pIC} 20 \mathrm{H}$ & This study \\
\hline pRCH04 & $\begin{array}{l}339 \text { bp EcoRI-BamHI fragment from pCH04 into the EcoRI site of pRSZ6 } \\
\text { (cagA-lacZ) }\end{array}$ & This study \\
\hline pCS141 & $m c p A-l a c Z$ in pLAC290 & $\begin{array}{l}\text { C. Stephens* } \\
\text { (unpublished) }\end{array}$ \\
\hline pCS44 & fliL-lacZ in pLAC290 & $\begin{array}{l}\text { Stephens \& Shapiro } \\
\text { (1993) }\end{array}$ \\
\hline pLAC290 & pRK290 containing a promoterless lacZ gene & Gober \& Shapiro (1992) \\
\hline pCS139 & tacp-lacZ in pLAC290 & $\begin{array}{l}\text { C. Stephens* } \\
\text { (unpublished) }\end{array}$ \\
\hline pWZ162 & fliQ-lacZ in pLAC290 & Zhuang \& Shapiro (1995) \\
\hline pBMSK6 & $5 \cdot 8 \mathrm{~kb}$ Bam HI fragment containing cagA into pBluescript SKII + & This study \\
\hline
\end{tabular}

*C. Stephens, Department of Biology, Santa Clara University, Santa Clara, CA, USA.

\section{RESULTS}

\section{Transcriptional start sites of $m c p A$ and $\operatorname{cag} A$}

The transcriptional start site for $m c p A$ was determined by primer extension using a primer (MCPA1) which was complementary to the coding strand 12 bp downstream of the ATG translational start codon (Fig. 2a). Three major extension products were observed, which is in strong agreement with the data obtained from S1nuclease mapping (data not shown). The -10 region (Fig. 2c) was unlike that defined for C. crescentus biosynthetic promoters, GCTANAWC, which has been shown to be used by the RpoD RNA polymerase holoenzyme (Malakooti et al., 1995). The mcpA - 10 region bore some similarity (4/8 matches) to the FliA $\left(\sigma^{28}\right)-10$ consensus sequence (Helmann \& Chamberlin, 1988) but the -35 region was even more divergent (Fig. 2c). No similarity to the consensus -35 sequence for biosynthetic promoters was observed (Malakooti et al., 1995). A putative CtrA-binding site was detected, but only 5 out of 9 residues matched the proposed consensus sequence, TTAA-N ${ }_{7}$-TTAAC (Marczynski et al., 1995; Quon et al., 1996). Neither half-site was completely conserved with the consensus motif.

In the process of constructing lac $Z$ fusions to the $m c p A$ promoter we identified an additional promoter. Transcription was divergent from the $m c p A$ promoter and the transcribed gene encoded a predicted ORF of $311 \mathrm{bp}$ (Fig. 1). We have designated this ORF $\operatorname{cag} A$, for chemotaxis associated gene $\underline{A}$, because it is located between two chemoreceptors (Fig. 1). No homologues of CagA were identified using BLAST, PSI-BLAST or FASTA3 analyses and no observable phenotype was associated with a knock-out mutant. However, the proximity of $\operatorname{cag} A$ to the major chemotaxis operon might indicate some level of co-regulation. In order to test this hypothesis we began by determining the transcriptional start site for $\operatorname{cag} A$. Two separate experiments utilizing different primers (CAGA1, CAGA2) confirmed the start site of $\operatorname{cag} A$ to be $57 \mathrm{bp}$ upstream of the deduced 
(a)

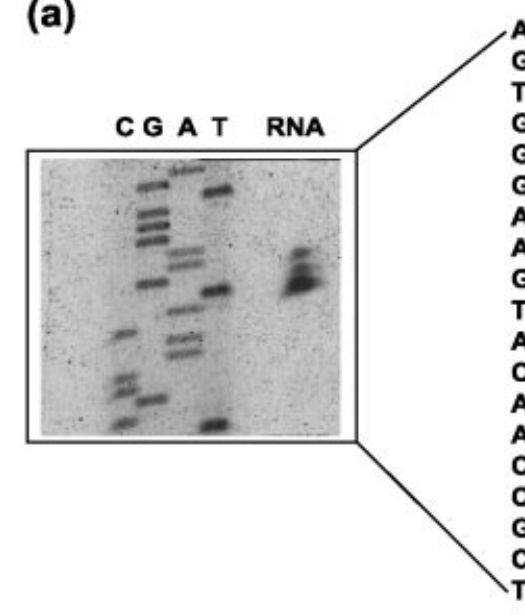

(c) (b)

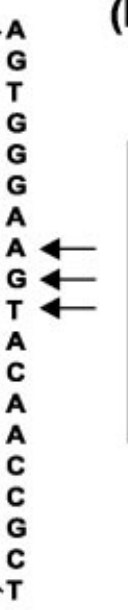

met

CAT CCCGCTGCTCCTAGTAAT

\section{GAATTCACGTCCTGTGGACGACGCGCCAACTGGACGCA GGAGCAAATTCGCAGG \\ $\operatorname{cag} A$ \\ CtrA? \\ TGCAAAGTTAAGATATTCTAGTCGCACGGTAAGATGCGGTTTACTTTCAGG \\ $-20 \div-30 \quad-40 \quad-50$}

TAACCACGATCTGCCGCTTTGGTGACTCTCATTGTGCGGCGAGGGTTTCGCAGA

TTCCATGCGGCGGAGCCTGCGACCAAACGACCACATGCTCCAAAATGGGACGAA

Ctra?
AATCTCTGACTTCCTTTAACCAAGTCAGAGTCTGTTAGGAATCTATCGGGATTA

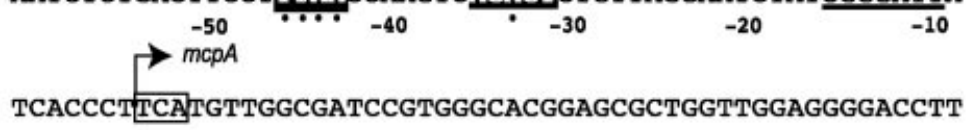

GCG ATG AAA CGG ATC C

met

(d)

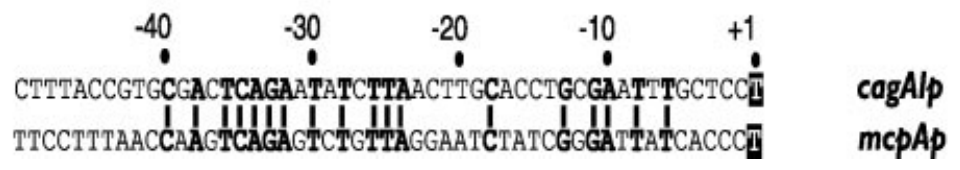

Fig. 2. (a, b) Primer extension to determine transcriptional start sites. Start sites were determined by primer extension and products were analysed by denaturing PAGE alongside a sequencing ladder derived from the same primer. The arrows indicate the start sites for (a) $m c p A$ and (b) cagA. (c) DNA sequence of the promoter region (GenBank accession no. X66502). Start sites for cagA and $m c p A$ are boxed; the black boxes indicate putative CtrA-binding motifs. Dots indicate residues identical to the CtrA consensus motif. Underlined sequences are putative FliA $\left(\sigma^{28}\right)$-binding motifs. Dotted arrows represent a direct repeat. Numbers along the DNA sequence indicate spacing from the respective start sites. (d) Alignment of the cagA and $m c p A$ promoters. The numbers indicate the spacing from the start of transcription. Residues in bold are conserved between the mcpA and cagA promoters.

translation initiation codon (Fig. 2b, c). Analysis of the upstream sequence (Fig. 2c) indicated a poor match to the -10 consensus sequence for the housekeeping sigma factor (Malakooti et al., 1995). A good match to the consensus binding motif for CtrA was identified, with 7 out of 9 residues conserved with the established consensus (Fig. 2c). In this instance the downstream halfsite (nearest to the transcriptional start site) is completely conserved. When the $m c p A$ and $c a g A$ promoters are aligned according to their transcriptional start sites 


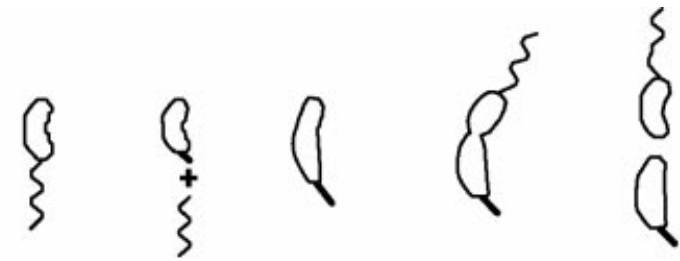

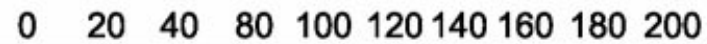

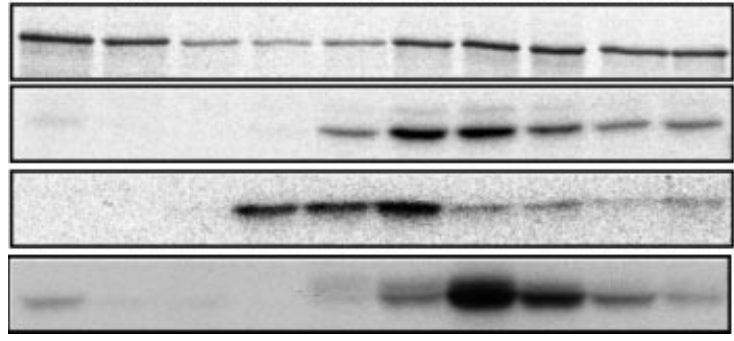

cagA-lacZ

McpA

CtrA

Flagellins
Fig. 3. Cell cycle transcription of $\operatorname{cag} A$. Strain MRKA779 harbouring a plasmidborne cagA-lacZ transcriptional fusion was synchronized and allowed to proceed through the cell cycle. After SDS-PAGE, immunoprecipitated labelled proteins were visualized by autoradiography. The same labelled cell extracts were immunoprecipitated with antisera to flagellin, McpA and CtrA as appropriate controls. Time points $(\mathrm{min})$ correlate with stages of the cell cycle as illustrated by the drawings above the panels. Cell cycle stages were monitored by light microscopy.
(Fig. 2d) we noticed that there was a stretch of identical residues (10/13 residues) around the -35 promoter region, which might indicate a shared regulator. If $\operatorname{cag} A$ and $m c p A$ share a common regulator then the cagAp should be cell cycle regulated.

\section{Transcription of $m c p A$ and cagA is temporally regulated}

To test this hypothesis we investigated the timing of transcription of the $\operatorname{cag} A$ gene using a promoterless lac $Z$ gene fused to the cagA promoter (pRCH04). Cells harbouring pRCH04 were synchronized as described in Methods. Swarmer cells were allowed to proceed synchronously through the cell cycle and were pulselabelled with $\left.{ }^{35} \mathrm{~S}\right]$ methionine at various times during the cell cycle. As controls we used antisera to flagellin and the global regulator CtrA. The cell cycle expression of the flagellins showed the same pattern as seen by Osley et al. (1977), with maximal flagellin gene transcription in late predivisional cells. The global regulator CtrA was transcribed before $c a g A$ and $m c p A$ (Fig. 3). Expression of $m c p A$ and the $c a g A-l a c Z$ transcriptional fusion was maximal at $120 \mathrm{~min}$ (Fig. 3). The main difference between $m c p A$ and $c a g A$ expression was that in swarmer cells there was significant synthesis of LacZ from the cagA-lacZ promoter fusion. Synthesis of the $25 \mathrm{kDa}$ flagellin (FljK) also occurred in the swarmer cell population. Synthesis of the $25 \mathrm{kDa}$ flagellin in the swarmer cell is due to segregation of the $\lg K \mathrm{mRNA}$ to the swarmer cell following cell division (Milhausen \& Agabian, 1983). To determine if a similar mechanism applied to $\operatorname{cag} A$, we tested the cagA-lac $Z$ promoter fusion, which has 36 bases of untranslated cagA mRNA, in a segregation experiment.

\section{The cagA transcript is targeted to the swarmer cell}

Cells harbouring the plasmid pRCH04 were synchronized as described previously, and swarmer cells were allowed to proceed through the cell cycle. At the late predivisional stage, cells were pulse-labelled with

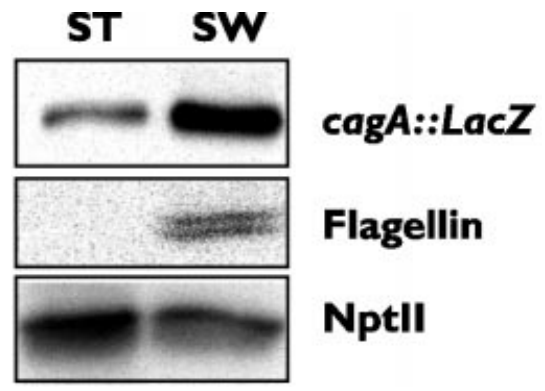

Fig. 4. Segregation of $\operatorname{cag} A$ transcript following cell division. MRKA779 harbouring pRCH04 (cagA-lacZ) was synchronized, allowed to proceed through the cell cycle, and after pulselabelling for $10 \mathrm{~min}$ with $\left.{ }^{35} \mathrm{~S}\right]$ methionine at the predivisional stage (140 min), cells were allowed to divide. Swarmer and stalked cell populations were separated by Percoll density centrifugation. After SDS-PAGE, labelled immunoprecipitated proteins were visualized by phosphorimager analysis. Flagellin and Nptll were included as positive and negative controls respectively. ST, stalked cell fraction; SW, swarmer cell fraction.

$\left[{ }^{35} \mathrm{~S}\right]$ methionine for $10 \mathrm{~min}$, then chased with an excess of non-radioactive methionine. Following cell division, swarmer and stalked cells were separated by Percoll density-gradient centrifugation. Labelled proteins were immunoprecipitated and localization of proteins was determined. Fig. 4 shows that most of the labelled cagAp-directed $\beta$-galactosidase was specifically targeted to the swarmer cells, suggesting that the presence of $\operatorname{cag} A$ mRNA in swarmer cells is due to specific targeting of the transcript. NptII was used as a non-segregated control and as expected was equally distributed between swarmer and stalked cell fractions (Fig. 4).

\section{DNA replication is required for $m c p A$ and $\operatorname{cag} A$ transcription}

Cell division and flagellum biogenesis are dependent on completion of chromosome replication (Osley \& Newton, 1980; Osley et al., 1977). Additionally class II flagellar gene promoters fliQp, fliFp and fliLp are 
Table 2. Effect of inhibition of DNA synthesis on promoter activity

Exponentially growing cultures of MRKA779 harbouring pRCH04 (cagA-lacZ) or pCS141 (mcpA-lacZ) were treated with $\mathrm{HU}$ at time zero. Equivalent counts from each sample were immunoprecipitated with antibodies to $\beta$-galactosidase, NptII or flagellin. Immunoprecipitated samples from each timepoint after HU addition were analysed by SDS-PAGE and labelled proteins were visualized by phosphorimager analysis. Quantitation was with IPLab Gel software. Expression levels for each time point are shown as a percentage relative to the maximum intensity observed at time zero (HU addition).

\begin{tabular}{|ccccc|}
\hline $\begin{array}{c}\text { Time } \\
(\mathbf{m i n})\end{array}$ & $\boldsymbol{m} \boldsymbol{c} \boldsymbol{p} \boldsymbol{c a g} \boldsymbol{A}$ & $\boldsymbol{n p t I I}$ & $\begin{array}{c}\mathbf{2 5} \mathbf{k D a} \\
\text { flagellin }\end{array}$ \\
\hline 0 & 100 & 100 & 100 & 100 \\
10 & $24 \cdot 3$ & 51 & 82 & $50 \cdot 8$ \\
20 & $14 \cdot 49$ & 28 & 76 & 47 \\
30 & $13 \cdot 6$ & 33 & 82 & 35 \\
40 & 5 & $25 \cdot 8$ & 70 & 37 \\
50 & $7 \cdot 6$ & 26 & 77 & 35 \\
60 & $3 \cdot 5$ & 16 & 70 & 18 \\
70 & $2 \cdot 3$ & $7 \cdot 6$ & 68 & $5 \cdot 7$ \\
\hline
\end{tabular}

Table 3. Effect of class II and class III flagellar mutants on the promoter activity of $m c p A p$ and cagAp

Plasmids pCS141 and pRCH04, which report the transcriptional activity of $m c p A$ and $\operatorname{cag} A$, were introduced into various class II and class III flagellar mutants and $\beta$ galactosidase activity was measured according to Miller (1972). Experiments were carried out five times, with duplicate assays each time. These data are mean values and are presented as a percentage compared to wild-type. The standard deviations ranged from 5 to $15 \%$.

\begin{tabular}{|c|c|c|c|}
\hline & $\begin{array}{l}\text { Flagellar } \\
\text { mutant }\end{array}$ & $\begin{array}{c}m c p A-l a c Z \\
(\%)\end{array}$ & $\begin{array}{c}\operatorname{cag} A-\operatorname{lac} Z \\
(\%)\end{array}$ \\
\hline \multirow{6}{*}{ Class II } & Wild-type & 100 & 100 \\
\hline & $f l i F$ & 205 & 142 \\
\hline & fliM & 206 & 140 \\
\hline & $\operatorname{flh} A$ & 197 & 129 \\
\hline & $f l b D$ & 169 & 155 \\
\hline & $r p o N$ & 226 & 154 \\
\hline \multirow[t]{3}{*}{ Class III } & $f l b G f l g D E$ & 158 & 141 \\
\hline & $f l g H$ & 150 & 130 \\
\hline & $f \lg K L$ & 159 & 111 \\
\hline \multirow[t]{2}{*}{ Chemotaxis } & $\Delta c h e 10$ & 153 & 161 \\
\hline & $\Delta c h e 491$ & 153 & 129 \\
\hline
\end{tabular}

sensitive to an interruption in DNA replication (Dingwall et al., 1992b). Like the class II flagellar genes, $m c p A$ and $\operatorname{cag} A$ are expressed differentially during the cell cycle; therefore it is important to ascertain whether replication of the chromosome is a prerequisite for transcription. Transcription of $m c p A$ and $\operatorname{cag} A$ was measured using plasmid-borne transcriptional fusions of $m c p A$ and $c a g A$ to a promoterless $\beta$-galactosidase gene (pCS141, pRCH04). The DNA replication inhibitor hydroxyurea (HU) was added to exponentially growing cultures of wild-type cells harbouring pCS141 and pRCH04. Cells were pulse-labelled at 10 min intervals after addition of $\mathrm{HU}$, followed by immunoprecipitation with anti- $\beta$-galactosidase antibody. Immunoprecipitation of NptII and flagellin was employed as a control. A significant decrease of $75 \%$ for $m c p A$ and $50 \%$ for cagA was observed by $10 \mathrm{~min}$ post addition of $\mathrm{HU}$ (Table 2). In comparison, transcription of the $n p t I I$ gene was relatively unaffected, since $70 \%$ expression levels remained 70 min post-HU addition. An $80 \%$ decrease in transcription of flagellin gene promoters was observed $60 \mathrm{~min}$ post addition of $\mathrm{HU}$, in accordance with previous observations (Osley \& Newton, 1980; Osley et al., 1977). The mcpA and $c a g A$ promoters are sensitive to a block in DNA synthesis. Since the effect of inhibiting DNA replication could be mediated by the class II flagellar genes, it was essential to determine the dependence of $m c p A$ and $c a g A$ transcription on class II gene expression. In the $E$. coli flagellar hierarchy chemotaxis genes are classified as class III genes along with flagellin gene $f l i C$.

\section{Where are the $m c p A$ and cagA genes in the Caulobacter transcriptional hierarchy?}

We tested the expression of the mcpA and $\operatorname{cag} A$ promoters fused to lacZ in various class II and class III flagellar mutants. Both promoters showed an increase in expression in all class II mutants tested (Table 3), which is a common feature of class II promoters. This indicated that the major chemotaxis operon has a class II promoter. This situation is very different from that found in E. coli, where chemotaxis gene expression requires the expression of class II genes. The $m c p A$ and $\operatorname{cag} A$ promoters show elevated levels of expression in class III flagellar mutants (Table 3 ). This is not usually observed with the archetypal class II promoters, but it is seen with the flhA promoter (Newton et al., 1989). To test whether any genes in the major chemotaxis operon play a part in regulation of $m c p A p$ or $\operatorname{cag} A p$ we determined their levels of expression in two chemotaxis deletions (Table 3). Both chemotaxis deletions caused an increase in expression from both promoters, suggesting that there may be some level of autoregulation.

\section{CtrA positively regulates transcription of $m c p A$ and $\operatorname{cag} A$}

CtrA is the master regulator of the flagellar gene regulon in C. crescentus (Quon et al., 1996). This two-component response regulator acts in either a positive or negative regulatory manner to activate or repress expression of several genes involved in flagellar biogenesis, chromosome replication (Marczynski et al., 1995) and lipopolysaccharide production (Leclerc et al., 1998). Since $c a g A$ and $m c p A$ expression is not abolished in class II flagellar mutants we determined whether $\operatorname{ctr} A$ 
Table 4. CtrA regulation of $m c p A$ and $\operatorname{cag} A$ promoters

The $\operatorname{ctr} A$ xylose-conditional strain (MRKA520) harbouring reporter plasmids pCS141 (mcpA-lacZ), pRCH04 (cagA-lacZ), pCS44 (filL-lacZ), pWZ162 (fliQ-lacZ) or pCS139 (tacp-lacZ) was grown to $\mathrm{OD}_{600} 0 \cdot 8$ in PYE plus xylose and washed to remove the inducer xylose as described in Methods. At hourly time points, samples were withdrawn and the activity of the $\beta$-galactosidase reporter gene assessed (Miller, 1972). Figures are given as percentage activity compared to the activity of the promoter at time zero. Experiments were carried out three times and the numbers are means \pm SD.

\begin{tabular}{|cccccc|}
\hline $\begin{array}{c}\text { Time } \\
(\mathbf{h})\end{array}$ & $\boldsymbol{m c p} \boldsymbol{A - l a c Z}$ & cagA-lacZ & tacp-lac $\boldsymbol{Z}^{*}$ & fliQ-lacZ $\dagger$ & fliL-lacZ $\dagger$ \\
\hline 0 & $100 \pm 0$ & $100 \pm 0$ & $100 \pm 0$ & $100 \pm 0$ & \\
1 & $105 \pm 7$ & $73 \pm 6$ & $108 \pm 9$ & $97 \pm 12$ & $89 \pm 4$ \\
2 & $90 \pm 7$ & $58 \pm 4$ & $112 \pm 19$ & $99 \pm 13$ & $99 \pm 2$ \\
3 & $69 \pm 2$ & $42 \pm 2$ & $140 \pm 12$ & $102 \pm 19$ & $56 \pm 9$ \\
4 & $51 \pm 8$ & $31 \pm 3$ & $88 \pm 8$ & $81 \pm 5$ & $64 \pm 5$ \\
5 & $47 \pm 1$ & $26 \pm 2$ & $108 \pm 21$ & $66 \pm 2$ & $51 \pm 2$ \\
\hline
\end{tabular}

* The tac promoter fused to lacZ was used as a control promoter that is not dependent on $c t r A$. † The fliQ-lacZ and fliL-lacZ promoter fusions are controls for $\operatorname{ctr} A$-dependent genes (Quon et al., 1996).

was required for the expression of these genes. Because the $\operatorname{ctr} A$ gene is essential we used a strain that has $\operatorname{ctr} A$ under the control of an inducible xylose promoter (Quon et al., 1996). Therefore, we can determine if CtrA regulates a promoter by removing xylose from the growth medium and measuring the change in $\beta$ galactosidase reporter gene activity. In these experiments, CtrA is not detectable in a Western blot after $2 \mathrm{~h}$ of xylose depletion (data not shown). Since $\beta$ galactosidase is a stable protein we are observing dilution of $\beta$-galactosidase activity in the cells. The $f i Q$ and $f l i L$ promoters fused to a $\beta$-galactosidase reporter gene were used as controls for CtrA-dependent expression (Quon et al., 1996; Wu et al., 1998) and as expected the levels of $\beta$-galactosidase activity dropped when xylose was depleted (Table 4). The tac promoter was used as a non-ctrA regulated promoter (Table 4). The $\beta$-galactosidase activity expressed from the $m c p A$ and $\operatorname{cag} A$ promoters started to drop within $2 \mathrm{~h}$ of xylose depletion (Table 4), which suggests that like fliQp and fliLp, $m c p A p$ and $c a g A p$ are regulated by $c t r A$.

\section{DISCUSSION}

\section{Targeting of cagA mRNA}

The structural components of the flagellar filament, FljKMNO, are synthesized in swarmer cells. However, most of the flagellar genes, including those for the components of the basal body, switch and hook, are not expressed in swarmer cells. In the case of the FljK flagellin, mRNA is specifically targeted to the swarmer cell. The $f l j K$ gene is not transcribed in swarmer cells and it is the stability of the $f l K \mathrm{mRNA}$ that ensures its presence in this cell type (Milhausen \& Agabian, 1983). Therefore it is unusual that $\operatorname{cag} A$ is expressed in swarmer cells. The kinetics of $\beta$-galactosidase synthesis from the cagA-lacZ promoter fusion after the addition of $\mathrm{HU}$ are similar to those seen with the FljK flagellin (Table 3). Perhaps the most likely explanation for the apparent synthesis of CagA in swarmer cells is that it is due to mRNA stability, as demonstrated for $f j K$ mRNA (Milhausen \& Agabian, 1983). Like $f l K$, cagA transcripts are preferentially targeted to the swarmer cell upon division of the predivisional cell. Deletion analyses of the $f l j K$ mRNA showed that sequences $5^{\prime}$ to the translation start codon are sufficient to impose regulation (Anderson \& Newton, 1997). The $f j K$ mRNA has a dramatically shorter half-life in the absence of flagellar assembly and it is proposed that FlbT mediates this by binding to the untranslated mRNA region (UTR) of $f l j K$ (Anderson \& Gober, 2000; Mangan et al., 1999). In our cagA-lac Z construct there are 36 bases of untranslated cag $A$ mRNA. However, there is no significant homology between the UTR of $c a g A$ and $f l j K$ to suggest that $\operatorname{cag} A$ is regulated by a similar mechanism to $f j K$.

\section{How does CtrA regulate $m c p A p$ and cagAp?}

The putative CtrA-binding motif in the $m c p A$ promoter is very poor, since only 5 out of 9 residues match. The $\operatorname{cag} A$ promoter has a putative motif which matches 7 out of 9 residues found in the CtrA consensus. However, the putative CtrA-binding motif in cagAp is slightly closer to the start of transcription when compared to CtrAbinding sites found in most class II flagellar promoters (Fig. 5). The absence of a well-conserved CtrA motif centred around the -35 region in both promoters may suggest that the effect of CtrA on these promoters is indirect. Furthermore, alignment of the cagA and mcpA promoters (Fig. 2d) revealed significant identity in the -35 region, perhaps indicative of a binding site for a shared regulator. The primary region where there is most identity coincides with the region where the upstream consensus CtrA half-site would be positioned (compare Fig. 2d and Fig. 5). Further evidence to suggest 


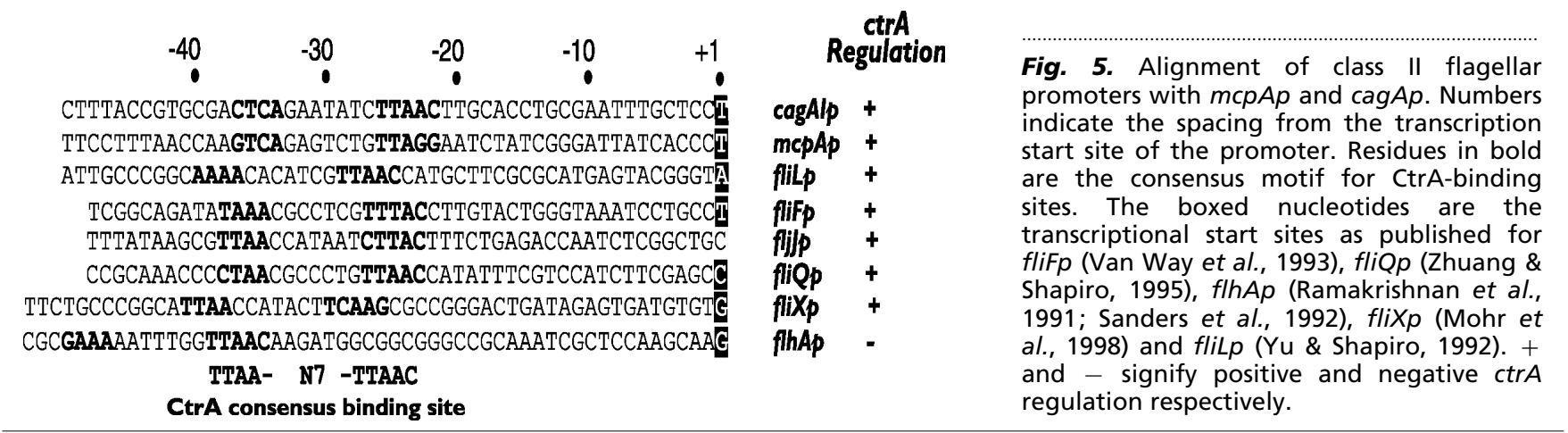

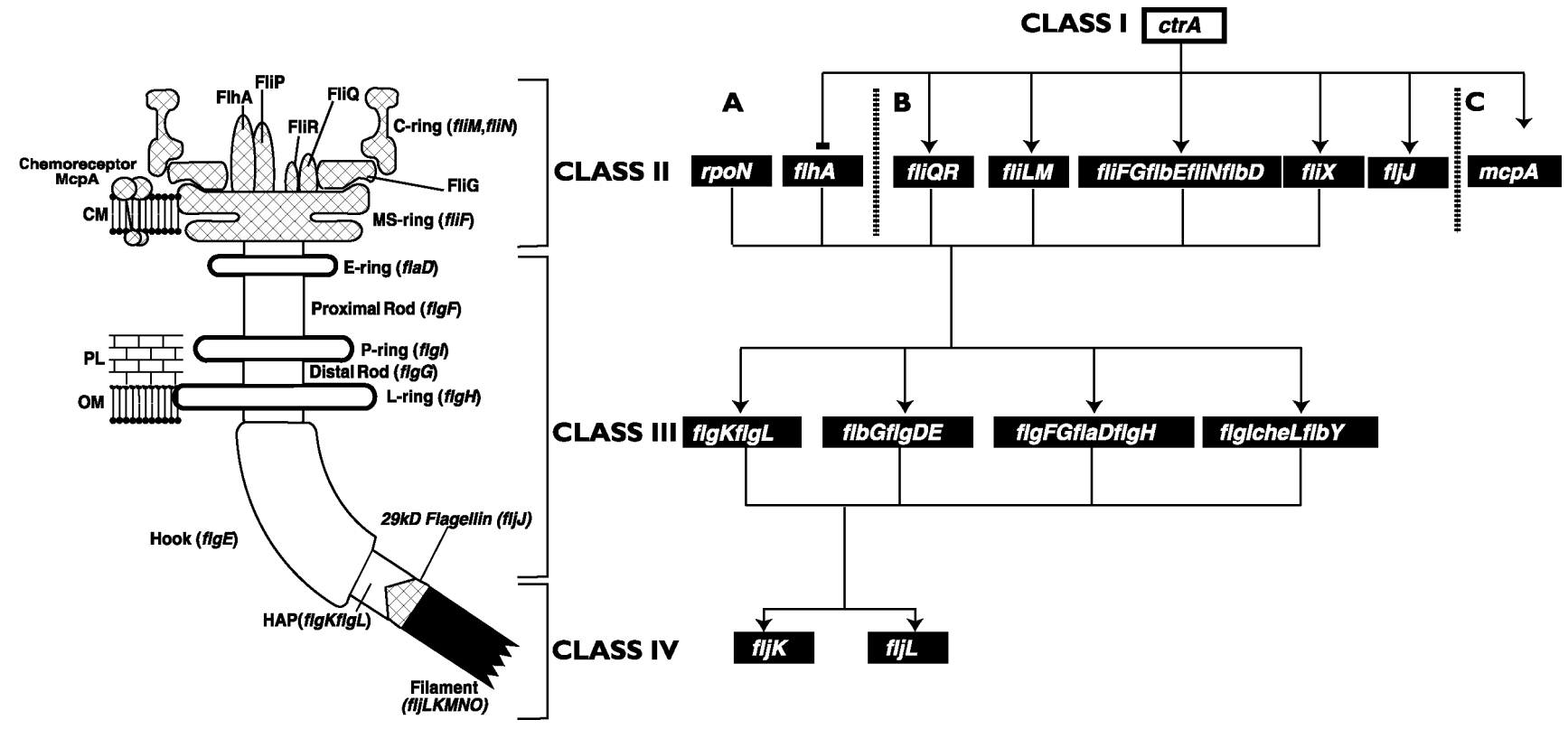

Fig. 6. Flagellar and chemotaxis hierarchy in C. crescentus. The figure on the left depicts the structure of the $C$. crescentus flagellum, with the flagellar gene products patterned according to their place in the transcriptional hierarchy: crosshatched (class II), white (class III) and black (class IV). CM, cytoplasmic membrane; PL, peptidoglycan layer; OM, outer membrane; HAP, hook-associated protein. The figure on the right shows the hierarchy as a traditional flow diagram with the dashed bars showing the separation between the different subclasses of the class II genes. Each black box denotes separate transcriptional units.

that the mcpA promoter is different from other CtrAdependent class II promoters is provided by the finding that transcription of $m c p A$ is inhibited when membrane synthesis is blocked (Brassinga et al., 2000), whilst other flagellar class II promoters are not affected. Finally, although we have been able to obtain a DNase I footprint of the fliQ promoter with CtrA we have been unsuccessful in binding CtrA to the mcpA promoter (S. E. Jones, unpublished). As demonstrated in this study and elsewhere, expression of an increasing number of genes is dependent on CtrA. However, many of these promoters reveal a complex pattern of regulation; for example $\mathrm{flm}$ genes (Leclerc et al., 1998) are subject to positive regulation by CtrA but their putative promoters do not possess any good sites for CtrA binding. No transcription of flagellar or chemotaxis genes has been detected in swarmer cells despite the presence of CtrA (Domian et al., 1997). This implicates accessory factors, in addition to CtrA, which may influence the temporal expression of flagellar and chemotaxis genes (Reisenauer et al., 1999).

\section{Reclassification of flagellar and chemotaxis class II promoters}

Results of transcriptional epistasis taken together with analysis of CtrA-dependence of the promoters analysed in this study prompted a re-examination of the flagellar hierarchy. The class II genes have been previously classified in the C. crescentus flagellar hierarchy as being required for the expression of class III and IV genes, and more recently as being positively regulated by CtrA binding to their promoters. We propose that class II promoters should comprise three distinct subclasses: A, $\mathrm{B}$ and $\mathrm{C}$ (Fig. 6). The flhA promoter should be classified as IIA since it is expressed early in the cell cycle 
(Ramakrishnan et al., 1991; Sanders et al., 1992) and is negatively regulated by CtrA (data not shown). The archetypal class II promoters fliQp, fliLp and fliFp should be classified as IIB. FljJ, the earliest synthesized flagellin (Loewy et al., 1987), is still expressed in a hook mutant, and is positively regulated by CtrA (data not shown). Since fljJp does not require $\sigma^{54}$ or other class II genes for expression fljJ can be placed in class IIB. Further evidence that FljJ should be placed in a different class from the other flagellins is that blocking membrane synthesis abolishes synthesis of FljK and FljL flagellins but not that of the FljJ flagellin (Brassinga et al., 2000). Inspection of the putative promoter of fljJ identified a good candidate CtrA-binding motif (Fig. 5), which would suggest that CtrA directly regulates $f l j J$ like the other class IIB genes. Expression of the $m c p A$ operon is not dependent on any of the class II genes, including the sigma factor gene rpoN. As mentioned previously the $m c p A$ promoter does not have a CtrA consensus at the conserved position relative to the transcriptional start site. Thus, we propose that $m c p A p$ should be classified as class IIC.

This study has probed regulation of several flagellar and chemotaxis genes, and has revealed new subclasses within the flagellar and chemotaxis hierarchy. Interruption of DNA synthesis prevented expression of $c a g A$ and $m c p A$, indicating that transcription of these genes was triggered by DNA replication, in common with other members of the flagellar regulon. The closest homologue to FliA in C. crescentus, SigX, does not impact on chemotaxis gene regulation (S. E. Jones \& M. R. K. Alley, unpublished). Instead chemotaxis gene regulation is mediated by CtrA, but other factors probably interact with CtrA-mediated regulation in order to facilitate cell-cycle control of the chemotaxis proteins. Chemotaxis gene regulation in C. crescentus is therefore significantly different from the E. coli paradigm.

\section{ACKNOWLEDGEMENTS}

This study was funded as a part of the BBSRC-CAD initiative (CAD05625). We would like to thank Ann Reinsenauer, Kim Quon and Lucy Shapiro for the $\operatorname{ctrA}$ strains and antisera. Preliminary sequence data were obtained from The Institute for Genomic Research website (http://www.tigr.org). Sequencing of C. crescentus was accomplished with support from the DOE. M.R.K.A. is a Royal Society University Research Fellow.

\section{REFERENCES}

Alley, M. R. K., Gomes, S. L., Alexander, W. \& Shapiro, L. (1991). Genetic analysis of a temporally transcribed chemotaxis gene cluster in Caulobacter crescentus. Genetics 129, 333-341.

Alley, M. R. K., Maddock, J. R. \& Shapiro, L. (1992). Polar localization of a bacterial chemoreceptor Genes Dev 6, 825-836.

Anderson, D. K. \& Newton, A. (1997). Posttranscriptional regulation of Caulobacter flagellin genes by a late flagellum assembly checkpoint. J Bacteriol 179, 2281-2288.

Anderson, P. E. \& Gober, J. W. (2000). FlbT, the post-trans- criptional regulator of flagellin synthesis in Caulobacter crescentus, interacts with the $5^{\prime}$ untranslated region of flagellin mRNA. Mol Microbiol 38, 41-52.

Brassinga, A. K., Gorbatyuk, B., Ouimet, M. C. \& Marczynski, G. T. (2000). Selective cell cycle transcription requires membrane synthesis in Caulobacter. EMBO J 19, 702-709.

Brun, Y. V. \& Shapiro, L. (1992). A temporally controlled sigmafactor is required for polar morphogenesis and normal cell division in Caulobacter. Genes Dev 6, 2395-2408.

Dingwall, A., Garman, J. D. \& Shapiro, L. (1992a). Organization and ordered expression of Caulobacter genes encoding flagellar basal body rod and ring proteins. J Mol Biol 228, 1147-1162.

Dingwall, A., Zhuang, W. Y., Quon, K. \& Shapiro, L. (1992b). Expression of an early gene in the flagellar regulatory hierarchy is sensitive to an interruption in DNA replication. J Bacteriol 174, 1760-1768.

Domian, I. J., Quon, K. C. \& Shapiro, L. (1997). Cell type-specific phosphorylation and proteolysis of a transcriptional regulator controls the G1-to-S transition in a bacterial cell cycle. Cell 90, 415-424.

Ely, B. (1991). Genetics of Caulobacter crescentus. Methods Enzymol 204, 372-384.

Ely, B. \& Ely, T. W. (1989). Use of pulsed field gel electrophoresis and transposon mutagenesis to estimate the minimal number of genes required for motility in Caulobacter crescentus. Genetics 123, 649-654.

Ely, B., Gerardot, C. J., Fleming, D. L., Gomes, S. L., Frederikse, P. \& Shapiro, L. (1986). General nonchemotactic mutants of Caulobacter crescentus. Genetics 114, 717-730.

Ely, B., Ely, T. W., Crymes, W. B., Jr \& Minnich, S. A. (2000). A family of six flagellin genes contributes to the Caulobacter crescentus flagellar filament. J Bacteriol 182, 5001-5004.

Gober, J. W. \& Shapiro, L. (1992). A developmentally regulated Caulobacter flagellar promoter is activated by $3^{\prime}$ enhancer and IHF binding elements. Mol Biol Cell 3, 913-926.

Helmann, J. D. \& Chamberlin, M. J. (1988). Structure and function of bacterial sigma factors. Annu Rev Biochem 57, 839-872.

Laub, M. T., McAdams, H. H., Feldblyum, T., Fraser, C. M. \& Shapiro, L. (2000). Global analysis of the genetic network controlling a bacterial cell cycle. Science 290, 2144-2148.

Leclerc, G., Wang, S. P. \& Ely, B. (1998). A new class of Caulobacter crescentus flagellar genes. J Bacteriol 180, 5010-5019.

Loewy, Z. G., Bryan, R. A., Reuter, S. H. \& Shapiro, L. (1987). Control of synthesis and positioning of a Caulobacter crescentus flagellar protein. Genes Dev 1, 626-635.

Malakooti, J., Wang, S. P. \& Ely, B. (1995). A consensus promoter sequence for Caulobacter crescentus genes involved in biosynthetic and housekeeping functions. J Bacteriol 177, 4372-4376.

Mangan, E. K., Malakooti, J., Caballero, A., Anderson, P., Ely, B. \& Gober, J. W. (1999). FlbT couples flagellum assembly to gene expression in Caulobacter crescentus. J Bacteriol 181, 6160-6170.

Marczynski, G. T., Lentine, K. \& Shapiro, L. (1995). A developmentally regulated chromosomal origin of replication uses essential transcription elements. Genes Dev 9, 1543-1557.

Milhausen, M. \& Agabian, N. (1983). Caulobacter flagellin mRNA segregates asymmetrically at cell division. Nature 302, 630-632.

Miller, J. H. (1972). Experiments in Molecular Genetics. Cold Spring Harbor, NY: Cold Spring Harbor Laboratory.

Mohr, C. D., MacKichan, J. K. \& Shapiro, L. (1998). A membraneassociated protein, FliX, is required for an early step in Caulobacter flagellar assembly. J Bacteriol 180, 2175-2185. 
Mullin, D. A. \& Newton, A. (1993). A sigma 54 promoter and downstream sequence elements $\mathrm{ftr} 2$ and $\mathrm{ftr} 3$ are required for regulated expression of divergent transcription units flaN and flbG in Caulobacter crescentus. J Bacteriol 175, 2067-2076.

Newton, A., Ohta, N., Ramakrishnan, G., Mullin, D. \& Raymond, G. (1989). Genetic switching in the flagellar gene hierarchy of Caulobacter requires negative as well as positive regulation of transcription. Proc Natl Acad Sci U S A 86, 6651-6655.

Nierman, W. C., Feldblyum, T. V., Paulsen, I. T. \& $\mathbf{3 4}$ other authors (2001). Complete genome sequence of Caulobacter crescentus. Proc Natl Acad Sci US A (in press).

Ninfa, A. J., Mullin, D. A., Ramakrishnan, G. \& Newton, A. (1989). Escherichia coli sigma 54 RNA polymerase recognizes Caulobacter crescentus flb $G$ and flaN flagellar gene promoters in vitro. J Bacteriol 171, 383-391.

Ohta, N., Swanson, E., Ely, B. \& Newton, A. (1984). Physical mapping and complementation analysis of transposon Tn5 mutations in Caulobacter crescentus: organization of transcriptional units in the hook gene cluster. J Bacteriol 158, 897-904.

Osley, M. A. \& Newton, A. (1980). Temporal control of the cell cycle in Caulobacter crescentus: roles of DNA chain elongation and completion. J Mol Biol 138, 109-128.

Osley, M. A., Sheffery, M. \& Newton, A. (1977). Regulation of flagellin synthesis in the cell cycle of Caulobacter: dependence on DNA replication. Cell 12, 393-400.

Quon, K. C., Marczynski, G. T. \& Shapiro, L. (1996). Cell cycle control by an essential bacterial two-component signal transduction protein. Cell 84, 83-93.

Ramakrishnan, G. \& Newton, A. (1990). FlbD of Caulobacter crescentus is a homologue of the $\mathrm{NtrC}$ (NRI) protein and activates sigma 54-dependent flagellar gene promoters. Proc Natl Acad Sci U S A 87, 2369-2373.

Ramakrishnan, G., Zhao, J. L. \& Newton, A. (1991). The cell cycleregulated flagellar gene flbF of Caulobacter crescentus is homologous to a virulence locus $(l c r D)$ of Yersinia pestis. J Bacteriol 173, 7283-7292.

Reisenauer, A., Quon, K. \& Shapiro, L. (1999). The CtrA response regulator mediates temporal control of gene expression during the Caulobacter cell cycle. J Bacteriol 181, 2430-2439.

Salser, W., Gesteland, R. F. \& Bolle, A. (1967). In vitro synthesis of bacteriophage lysozyme. Nature 215, 588-591.

Sambrook, J., Fritsch, E. F. \& Maniatis, T. (1989). Molecular Cloning: a Laboratory Manual, 2nd edn. Cold Spring Harbor, NY: Cold Spring Harbor Laboratory.
Sanders, L. A., Van Way, S. \& Mullin, D. A. (1992). Characterization of the Caulobacter crescentus flbF promoter and identification of the inferred FlbF product as a homolog of the LcrD protein from a Yersinia enterocolitica virulence plasmid. J Bacteriol 174, 857-866.

Simon, R., Priefer, U. \& Puhler, A. (1983). A broad host range mobilization system for in vivo genetic engineering: transposon mutagenesis in gram negative bacteria. Bio/Technology 1, 784-791.

Stephens, C. M. \& Shapiro, L. (1993). An unusual promoter controls cell-cycle regulation and dependence on DNA replication of the Caulobacter fliLM early flagellar operon. Mol Microbiol 9, 1169-1179.

Tsai, J. W. \& Alley, M. R. K. (2000). Proteolysis of the McpA chemoreceptor does not require the Caulobacter major chemotaxis operon. J Bacteriol 182, 504-507.

Van Way, S. M., Newton, A., Mullin, A. H. \& Mullin, D. A. (1993). Identification of the promoter and a negative regulatory element, $\mathrm{ftr} 4$, that is needed for cell cycle timing of $\mathrm{fliF}$ operon expression in Caulobacter crescentus. J Bacteriol 175, 367-376.

Wingrove, J. A. \& Gober, J. W. (1996). Identification of an asymmetrically localized sensor histidine kinase responsible for temporally and spatially regulated transcription. Science 274, 597-601.

Wu, J. \& Newton, A. (1997). Regulation of the Caulobacter flagellar gene hierarchy; not just for motility. Mol Microbiol 24, 233-239.

Wu, J., Ohta, N. \& Newton, A. (1998). An essential, multicomponent signal transduction pathway required for cell cycle regulation in Caulobacter. Proc Natl Acad Sci USA 95, 1443-1448.

Xu, H., Dingwall, A. \& Shapiro, L. (1989). Negative transcriptional regulation in the Caulobacter flagellar hierarchy. Proc Natl Acad Sci U S A 86, 6656-6660.

Yu, J. \& Shapiro, L. (1992). Early Caulobacter crescentus genes fliL and $f i M$ are required for flagellar gene expression and normal cell division. J Bacteriol 174, 3327-3338.

Zhuang, W.-Y. \& Shapiro, L. (1995). Caulobacter FliQ and FliR membrane proteins, required for flagellar biogenesis and cell division, belong to a family of virulence factor export proteins. J Bacteriol 177, 343-356.

Received 21 September 2000; revised 4 January 2001; accepted 8 January 2001. 